Aim of the study: Matrix metalloproteinases (MMPs) are a zinc-dependant endopeptidase family that can degrade extracellular matrix components. Their dysregulation has been proven in several diseases, including cancer. Genetic variations in MMP promoter regions can alter their expression. The aim of the present study is to investigate the correlation of MMP-2 (-1306C/T), MMP-9 (-1562C/T), and MMP-12 (-82A/G) single nucleotide polymorphisms (SNPs) with oesophageal squamous cell carcinoma (ESCC) initiation and progression susceptibility in Iranian patients.

Material and methods: MMP-2 (-1306C/T), MMP-9 (-1562C/T), and MMP-12 (-82A/G) SNPs were detected using polymerase chain reaction-restriction fragment-length polymorphism (PCR-RFLP) technique in $70 \mathrm{pa}$ tients and 60 healthy controls. The genotypes and allele distributions were statistically compared in patients and controls. The correlation of MMP-2 (-1306C/T) and MMP-9 (-1562C/T) polymorphisms with clinicopathological features were investigated in 53 patients.

Results: No statistically significant differences were observed in genotype and allele frequencies of MMP-2 $(-1306 \mathrm{C} / \mathrm{T})$ and MMP-9 $(-1562 \mathrm{C} / \mathrm{T})$ between patients and controls $(p>0.05)$ In addition, no relevance was observed in MMP-2 (-1306C/T) and MMP-9 (-1562C/T) SNPs and clinicopathological features. There was no nucleotide variation in MMP-12 (-82) in the case and control groups.

Conclusions: This study indicates that these three SNPs may have no significant association in ESCC risk in Iranian patients.

Key words: matrix metalloproteinase, single nucleotide polymorphism, esophagus squamous cell carcinoma.

Contemp Oncol (Pozn) 2015; 19 (4): 300-305 DOI: $10.5114 /$ wo.2015.48569

\section{The influence of matrix}

metalloproteinase-2, -9 , and -12

promoter polymorphisms on Iranian patients with oesophageal squamous cell carcinoma

\author{
Haniehsadat Eftekhary ${ }^{1}$, Abed-Ali Ziaee ${ }^{1}$, Mansour Yazdanbod ${ }^{2}$, \\ Mitra Shahpanah ${ }^{3}$, Aziz Setayeshgar ${ }^{4}$, Mojgan Nassiri ${ }^{4}$
}

${ }^{1}$ Institute of Biochemistry and Biophysics, Tehran, Iran ${ }^{2}$ Department of Surgery, Madaen Hospital, Tehran, Iran ${ }^{3}$ Delivery Room, Bank Melli Iran Hospital, Tehran, Iran ${ }^{4}$ Pathology Department, Madaen Hospital, Tehran, Iran

\section{Introduction}

Oesophageal cancer is the world's eighth most prevalent malignancy and the sixth most common cause of cancer death [1]. It is characterised by poor prognosis, rapid progression, and low survival - 5-year survival is less than 5\% [2]. Histologically, oesophageal carcinoma occurs in two pathological forms: oesophagus squamous cell carcinoma (ESCC) in the middle or upper part of the oesophagus, and gastric cardia adenocarcinoma (GCA) in the lower part or junction of the oesophagus and the stomach. The incidence of oesophageal neoplasia varies considerably from high-risk areas like Africa and some parts of Asia to low-risk areas in western and central Africa and Central America [3]. North and northeast of Iran are regions with high occurrence of oesophageal cancer, and ESCC encompasses $>90 \%$ of all oesophageal malignancies in these areas [4]. Its rapid progression and invasive trait give the fatal property to ESCC. Tumour invasion and metastasis are multistep processes that are greatly facilitated by protease activities for destruction and remodelling of extracellular matrix (ECM) and basement membrane barriers. Studies in the past 50 years have considered Matrix metalloproteinases (MMPs) as primary molecules aiding tumour cells in metastasis processes [5]. These degradative enzymes are a family of $\mathrm{Zn}^{2+}$-dependent endopeptidases totally capable of decomposing all extracellular components [6]. Matrix metalloproteinases can implicate in tumour development by degradation of ECM and also by release of several ECM-bound biomolecules such as growth factors and agents involved in angiogenesis [7]. Among 24 members of the MMP family, MMP-2 and MMP-9, known as Gelatinases, by degradation of type IV collagen, the major component of basement membrane, have crucial roles in the early stages of tumour invasion [8]. Gelatinases also participate in tumour angiogenesis via enhancement of the bioavailability of pro-angiogenic factors such as VEGF $[9,10]$. MMP-12, human macrophage metalloelastase, degrades elastin, type IV collagen, opening the way for migration of tumour cells [11].

Matrix metalloproteinase expression, initially regulated at the transcriptional level, and alteration in cis element binding sites in their promoter can convert their expression. Multiple SNPs have been identified on MMP-2, MMP-9, and MMP-12 promoters [6]. Several studies performed in different populations of the world have demonstrated the influence of MMP-2 (-1306C/T), MMP-9 (-1562C/T), and MMP-12 (-82A/G) polymorphisms on different malignant cancers, such as digestive cancers $[12,13]$. In addition, 
some studies have shown overexpression of MMP-2 and MMP-9 in ESCC tumour cells and their association with tumour invasion $[14,15]$. Consequently, the present study was planned to evaluate whether these three polymorphisms are good prognostic markers for recognition and screening of susceptible individuals in high-risk areas of Iran.

\section{Material and methods}

\section{Study participants}

In this study, polymorphisms were analysed in two groups: case and control. The case group comprised $70 \mathrm{pa}-$ tients with ESCC, 37 (52.9\%) men and 33 (47.1\%) women, aged $34-81$ years with a mean age of 59.5 years. Pathological data of 55 patients were available and are described in Table 1. Control participants included 60 healthy individuals having no history or diagnosis of cancer or any serious disease, 30 (50\%) men and 30 (50\%) women, aged 28-75 with a mean age of 46.53 years.
The study was approved by the Ethics Committee of Tehran University of Medical Sciences.

\section{DNA extraction}

Tumour tissues were collected immediately after surgery in liquid nitrogen and stored at $-70^{\circ} \mathrm{C}$ until the time of use. In order to extract DNA, the tissue specimens were dissected and adipose and connective tissues were removed. Then the specimens were fragmented and suspended in buffer containing $0.15 \mathrm{mM} \mathrm{NaCl}, 10 \mathrm{mM}$ EDTA, and $10 \mathrm{mM}$ Tris- $\mathrm{HCl}, \mathrm{pH} 7.5$, and the lysis step was followed by the addition of $50-100 \mu \mathrm{g} / \mathrm{ml}$ proteinase $\mathrm{K}$ and SDS with a final concentration of $0.5 \%$. The lysate was incubated over night at $37^{\circ} \mathrm{C}$. It was then mixed with an equal volume of phenol and after gentle mixing, centrifuged at $14000 \mathrm{rpm}$ for five minutes. The supernatant was mixed with equal volumes of chloroform and isoamyl alcohol (24: 1$)$ and centrifuged at 14000 rpm for five minutes. Subsequently, the supernatant was diluted with 2.2 volume of

Table 1. Pathological data of oesophageal squamous cell carcinoma patients

\begin{tabular}{|c|c|c|c|c|c|}
\hline $\begin{array}{l}\text { Case } \\
\text { number }\end{array}$ & Differentiation & LMN & $\begin{array}{l}\text { Case } \\
\text { number }\end{array}$ & Differentiation & LMN \\
\hline 1 & * & + & 29 & Moderately to poorly differentiated & - \\
\hline 2 & Moderately differentiated & + & 30 & Well differentiated & + \\
\hline 3 & Well differentiated & - & 31 & Poorly differentiated & + \\
\hline 4 & Moderately differentiated & - & 32 & Moderately differentiated & + \\
\hline 5 & Well differentiated & - & 33 & Well differentiated & + \\
\hline 6 & Poorly differentiated & + & 34 & Moderately differentiated & + \\
\hline 7 & Moderately differentiated & + & 35 & Well differentiated & + \\
\hline 8 & Poorly differentiated & - & 36 & Well differentiated & + \\
\hline 9 & Moderately differentiated & - & 37 & Moderately differentiated & + \\
\hline 10 & Poorly differentiated & + & 38 & Moderately differentiated & - \\
\hline 11 & Poorly differentiated & + & 39 & Well differentiated & + \\
\hline 12 & Moderately to poorly differentiated & - & 40 & Moderately differentiated & + \\
\hline 13 & Poorly differentiated & + & 41 & Poorly differentiated & + \\
\hline 14 & Moderately differentiated & + & 42 & Moderately differentiated & + \\
\hline 15 & $\begin{array}{l}\text { Well differentiated } \\
\text { Moderately differentiated }\end{array}$ & - & 43 & Moderately differentiated & + \\
\hline 17 & Well differentiated & + & 44 & Well differentiated & + \\
\hline 18 & Moderately differentiated & + & 45 & Well differentiated & - \\
\hline 19 & Moderately differentiated & + & 46 & Well differentiated & - \\
\hline 20 & Moderately differentiated & - & 47 & Well differentiated & + \\
\hline 21 & Poorly differentiated & * & 48 & Moderately differentiated & + \\
\hline 22 & Moderately differentiated & - & 49 & Moderately differentiated & - \\
\hline 23 & Well differentiated & - & 50 & Well differentiated & + \\
\hline 24 & Poorly differentiated & - & 51 & Well differentiated & + \\
\hline 25 & Moderately differentiated & + & 52 & Moderately differentiated & + \\
\hline 26 & Moderately differentiated & + & 53 & Moderately differentiated & + \\
\hline 27 & Well differentiated & + & 54 & Well differentiated & * \\
\hline 28 & Well differentiated & + & 55 & Well differentiated & + \\
\hline
\end{tabular}

* data not available

LMN - lymph nod metastasis 
Table 2. Polymorphisms, primers, annealing temperatures, and size of fragments

\begin{tabular}{|c|c|c|c|}
\hline Polymorphism & Primer & $\begin{array}{c}\text { Annealing } \\
\text { temperature }\left({ }^{\circ} \mathrm{C}\right)\end{array}$ & Size (bp) \\
\hline MMP-2 (-1306C/T) & $\begin{array}{c}5^{\prime} \text {-CTTCCTAGGCTGGTCCTTACTGA-3’' Forward } \\
5^{\prime} \text {-CTGAGACCTGAAGAGCTAAAGAGCT-3’ Reveres }\end{array}$ & 66 & $193 \mathrm{bp}$ \\
\hline MMP-9 (-1562C/T) & $\begin{array}{c}5^{\prime} \text {-GCCTGGCACATAGTAGGCCC-3’ Forward } \\
\text { 5'-TCTCTCAGCCGGCATC-3’ Reveres }\end{array}$ & 65 & $435 \mathrm{bp}$ \\
\hline MMP-12 (-82A/G) & $\begin{array}{c}5^{\prime} \text {-GAGATAGTCAAGGGATGATATCA-3' Forward } \\
5^{\prime} \text {-AAGAGCTCCAGAAGCAGTGG-3' Reveres }\end{array}$ & 60 & 199 bp \\
\hline
\end{tabular}

Table 3. Restriction enzymes and fragment lengths

\begin{tabular}{|lcc}
\hline Polymorphism & $\begin{array}{c}\text { Restriction } \\
\text { enzyme }\end{array}$ & Fragment length \\
\hline MMP-2 $(-1306 C / T)$ & FspBl & $188+5$ bp C \\
& Sphl & $247+188$ bp T \\
MMP-9 $(-1562 C / T)$ & & 435 bp C \\
& Pvull & 199 bp A \\
MMP-12 $(-82 \mathrm{~A} / \mathrm{G})$ & & $175+24 \mathrm{bp} \mathrm{G}$
\end{tabular}

absolute ethanol. The precipitated DNA was washed with $70 \%$ ethanol. It was dried at room temperature. Finally it was dissolved in 100-200 $\mu \mathrm{l}$ TE buffer $(10 \mathrm{mM}$ Tris, $1 \mathrm{mM}$ EDTA, pH 7.5) and stored at $-20^{\circ} \mathrm{C}[16]$. In order to collect saliva from healthy volunteers, they were given screw-top containers and asked about an hour after brushing their teeth to spit vigorously about $30 \mathrm{ml}$ into the containers. Then samples were kept at $-20^{\circ} \mathrm{C}$ until the time of use. DNA was extracted from saliva by using the method of Lum and Marchand (1998) [17]. The collected DNA concentrations were evaluated by UV spectroscopy method, and then for evaluation of their molecular weight status they were run on $0.8 \%$ agarose gel stained with ethidium bromide.

\section{MMP-2 (-1306C/T), MMP-9 (-1562C/T) and MMP-12 (-82A/G) genotyping}

The MMP-2, MMP-9, and MMP-12 SNPs were determined using PCR-Restriction fragment length polymorphism (PCR-RFLP) assay. The amplification primers, their annealing temperatures, and the size of each fragment is shown in Table 2. Each PCR was performed in a total volume of $50 \mu \mathrm{l}$, containing $12.5 \mathrm{ng}$ DNA, $5 \mu \mathrm{l}$ 10X PCR buffer, $3.75 \mathrm{mM} \mathrm{MgCl}, 0.31 \mathrm{mM}$ dNTPs, $2.5 \cup$ Taq DNA polymerase, and $0.62 \mu \mathrm{M}$ forward and reveres primers. The PCR thermo cycling conditions for MMP-2 and MMP-12 were as follows: 5 minutes at $94^{\circ} \mathrm{C}$ at initial step followed by 35 cycles of 45 seconds at $94^{\circ} \mathrm{C}, 45$ seconds at $58^{\circ} \mathrm{C}$ for MMP-2 and $53^{\circ} \mathrm{C}$ for MMP- 12,45 seconds at $72^{\circ} \mathrm{C}$, with the final step at $72^{\circ} \mathrm{C}$ for 10 minutes. The cycling conditions for MMP-9 were started at $95^{\circ} \mathrm{C}$ for 5 minutes, followed by 35 cycles of 1 minute at $93^{\circ} \mathrm{C}, 30$ seconds at $61.8^{\circ} \mathrm{C}$, 50 seconds at $72^{\circ} \mathrm{C}$, and completed extension at $72^{\circ} \mathrm{C}$ for 5 minutes. $10 \mu \mathrm{l}$ of each PCR product was digested at $37^{\circ} \mathrm{C}$ overnight by $10 \mathrm{U}$ of appropriate restriction enzymes. FspBI, Sphl, and Pvull were used for MMP-2 (-1306C/T), MMP-9 (-1562C/T), and MMP-12 (-82A/G), respectively.
Products were separated on 3\% agarose gel staining with ethidium bromide. The fragment lengths of digested products are summarised in Table 3.

\section{Statistical analysis}

Statistical analysis was carried out using the SPSS 18 software package. The difference in distribution of alleles and genotypes between patients and controls was compared by two-sided chi-square test. The association of genotype and allele distributions with ESCC risk was evaluated by OR (odds ratio) with 95\% confidence interval (CI). The correlation between genotypes and clinicopathological characteristics, the tumour differentiation, and lymph node metastasis, was analysed by Fisher exact test. A 5\% probability value was considered significant.

\section{Results}

The detection of MMP-2 (-1306C/T), MMP-9 (-1562C/T), and MMP-12 (-82A/G) polymorphisms was performed well. The results in Table 4 show that this study did not demonstrate any statistically significant differences in allele and genotype distributions in MMP-2 $(-1306 \mathrm{C} / \mathrm{T})$ or MMP-9 $(-1562 C / T)$ between ESCC patients and controls $(p>0.05)$. The statistical analysis of these two polymorphisms did not show any correlation between genotype frequencies and ESCC risk (OR $=0.862$, 95\% Cl: 0.385-1.927 for MMP-2 and $\mathrm{OR}=1.092,95 \% \mathrm{Cl}:$ 0.541-2.206 for MMP-9). Pathological information, tumour differentiation, and lymph node metastasis of 55 patients was available in the current study; Fisher exact test was performed to determine the association of genotype frequency with tumour differentiation and lymph node metastasis (Table 5). There was no association between MMP-2 (-1306C/T) and MMP-9 (-1562C/T) genotype frequencies and tumour development $(p>0.05)$.

No single nucleotide polymorphisms were detected in MMP-12 (-82), and all the samples showed A allele in this site. The separated bands of each polymorphism on agarose gel are shown in Fig. 1.

\section{Discussion}

Single nucleotide polymorphisms (SNPs) are the most frequently inherited sequence variations in a particular gene, and they occur in every 100-200 base pairs [18]. Some SNPS on MMP-2 promoter have been identified; among these, MMP-2 (-1306C/T) has been reported by several studies to be more involved in many cancer types [19]. In MMP-2 at -1306, substitution of T allele instead of C disrupts the Sp1-binding site and leads to lower promoter ac- 
Table 4. Genotype and allele distributions of MMP-2 and MMP-9 single nucleotide polymorphisms.

\begin{tabular}{|c|c|c|c|c|}
\hline & $\begin{array}{c}\text { Controls } \\
n(\%)\end{array}$ & $\begin{array}{c}\text { Patients } \\
n(\%)\end{array}$ & OR $(95 \% \mathrm{Cl})$ & $P$ value (2-tail) \\
\hline \multicolumn{5}{|c|}{ MMP-2 $(-1306 \mathrm{C} / \mathrm{T})^{\dagger}$} \\
\hline CC & $46(76.7)$ & $51(73.9)$ & & \\
\hline CT & $10(16.7)$ & $17(24.6)$ & & \\
\hline TT & $4(6.7)$ & $1(1.4)$ & & \\
\hline$(\mathrm{CC}, \mathrm{CT}+\mathrm{TT})$ & & & $0.862(0.385-1.927)$ & $0.718 \quad \chi^{2}=0.1305$ \\
\hline C & $102(85)$ & $119(86.2)$ & & \\
\hline $\mathrm{T}$ & $18(15)$ & $19(13.8)$ & & \\
\hline$C, T$ & & & $1.105(0.55-2.219)$ & $0.778 \quad \chi^{2}=0.0792$ \\
\hline \multicolumn{5}{|c|}{ MMP-9(-1562C/T $)^{\ddagger}$} \\
\hline CC & $34(56.7)$ & $40(58.8)$ & & \\
\hline CT & $23(38.3)$ & $25(36.8)$ & & \\
\hline TT & $3(5)$ & $3(4.4)$ & & \\
\hline$(\mathrm{CC}, \mathrm{CT}+\mathrm{TT})$ & & & $1.092(0.541-2.206)$ & $\chi^{2}=0.0608$ \\
\hline C & $91(75.8)$ & $105(77.2)$ & & \\
\hline $\mathrm{T}$ & $29(24.2)$ & $31(22.8)$ & & \\
\hline$C, T$ & & & $1.079(0.605-1.926)$ & $0.796 \quad \chi^{2}=0.0669$ \\
\hline
\end{tabular}

tOne tumour sample was missed

$\neq$ Two tumour samples were missed

tivity, and investigations have shown that the presence of $C$ allele in this region enhances the promoter activity by as much as two times $[19,20]$. In our study the genotype distribution of MMP-2 (-1306C/T) was CC $73 \%$, CT $24 \%$, and TT $1.4 \%$ in patients and CC $76 \%$, CT $16.7 \%$, and TT $6.7 \%$ in the control group, i.e. there was no statistically significant difference between patients and controls $(p>0.05)$. Various studies on MMP-2 (-1306C/T) SNP and risk of different types of cancer did not report homogenous results in different populations of the world. Studies in China reported that, compared with CT and TT genotypes, CC genotype significantly increases susceptibility to oesophageal, lung, and breast cancers $[12,21,22]$. Additionally, a study in China on gastric cardia adenocarcinoma found that patients with CC genotype are at three-fold higher risk than those with CT and TT genotypes [13]. However, our investigation is in agreement with some studies from Japan, Turkey, and Sweden, which did not find any correlation between MMP-2 (-1306C/T) polymorphism and cancer [23-25]. Two Chinese meta-analysis studies demonstrated that T allele frequency is significantly lower in the Asian population (13.6\%) than in Europeans (23.3\%), which is in agreement with the results obtained from our study $(13-15 \%)$ [26, 27].

MMP-9 C to T transition at -1562 has been proven to decrease the affinity of the transcriptional repressive protein to bind to its site at MMP-9 promoter, which subsequently causes higher promoter function. The current study did not find any significant differences in distribution of genotypes and alleles in MMP-9 $(-1562 \mathrm{C} / \mathrm{T})$ between patients and healthy individuals (CC 58.8\%, CT 36.8\%, and TT $4.4 \%$ and CC 56.7\%, CT 38.3\%, and TT 5\% in patients and controls, respectively). Unfortunately a few investigations were carried out analysing the association of MMP-9 (-1562C/T) polymorphism with oesophageal cancer risk,
Table 5. Association of genotype distributions with clinicopathological characteristics

\begin{tabular}{|c|c|c|c|c|}
\hline \multirow[b]{2}{*}{ Differentiation } & \multicolumn{2}{|c|}{ MMP-2 (-1306C/T) } & \multicolumn{2}{|c|}{ MMP-9 $(-1562 C / T)$} \\
\hline & CC & $\mathrm{CT}, \mathrm{TT}$ & $\mathrm{CC}$ & $\mathrm{CT}, \mathrm{TT}$ \\
\hline Well & 15 & 4 & 13 & 7 \\
\hline Moderately & 17 & 6 & 11 & 10 \\
\hline Poorly & 7 & 4 & 8 & 3 \\
\hline$p$ value $(2 \text {-tail })^{\star}$ & \multicolumn{2}{|c|}{0.664} & \multicolumn{2}{|c|}{0.575} \\
\hline \multicolumn{5}{|l|}{ LMN } \\
\hline Positive & 26 & 10 & 22 & 14 \\
\hline Negative & 13 & 4 & 10 & 6 \\
\hline$p$ value (2-tail)* & \multicolumn{2}{|c|}{1.00} & \multicolumn{2}{|c|}{1.00} \\
\hline
\end{tabular}

$L M N$-lymph node metastasis

* $p$ value for Fisher's exact test

but the outcome obtained in the present study was consistent with other studies on different cancer types in Sweden, China, Tunisia, and France [25, 28-30].

We also analysed the association of these two polymorphisms with pathological characteristics, tumour differentiation, and lymph node metastasis; our findings did not show any association between genotype distribution of MMP-2 and MMP-9 SNPs and these pathological features.

The MMP-12 is located at chromosome 11q22, and the A to $G$ transition at the -82 region, the recognition site of AP-1 transcriptional factor, decreases the binding potential of AP-1 protein and modifies the MMP-12 expression in vitro [31]. All the samples in this study showed A allele in MMP-12 (-82) and no nucleotide variation was identified 

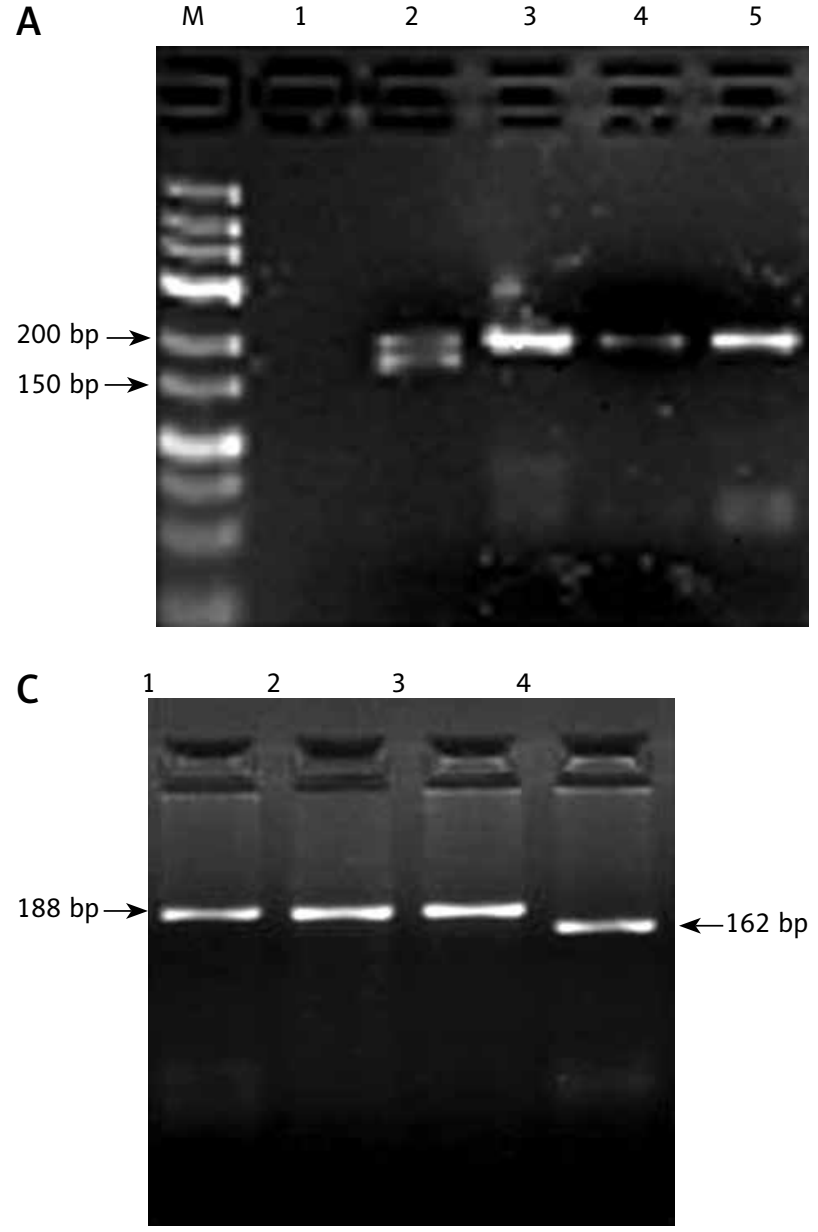

in MMP-12 (-82). Some previous studies have shown the influence of GG genotype in MMP-12 (-82) site on the risk of some cancers; one study in the US indicated that GG genotype in MMP-12 (-82) increased the risk of invasive bladder cancer about 4.5 fold [32]. The high frequency of A allele at position -82 has been reported in some studies. In the previous research in northern China the frequency of A allele has been reported to be more than 90\% [12]. This study suggested that the occurrence of MMP-12 (-82) A to $G$ transition may differ between variant populations.

Both environmental and genetic factors play roles in oesophageal squamous cell carcinoma outbreak [33]. Since individuals exposed to environmental risk factors show different susceptibility to ESCC, it seems that some genetic variations like genetic polymorphisms have been associated with oesophageal cancer development in Iran, and the discovery of influential polymorphisms on ESCC can be valuable markers for the identification of predisposed individuals in high-risk areas. Consequently, for the first time in this manuscript we analysed the role of MMP-2 (-1306C/T), MMP-9 (-1562C/T), and MMP-12 (-82A/G) polymorphisms in the development of ESCC in Iran.

We concluded that MMP-2 (-1306C/T), MMP-9 $(-1562 C / T)$, and MMP-12 (-82A/G) single nucleotide polymorphisms are not useful prognostic markers in the identification and screening of susceptible individuals in areas with high occurrence of oesophageal squamous cell carci-

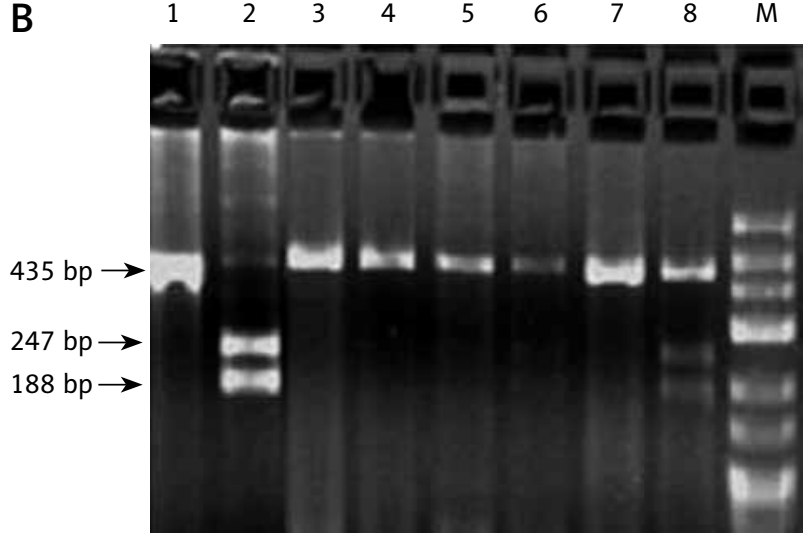

Fig. 1. Separated bands of MMP-2 (-1306C/T), MMP-9 (-1562C/T) polymorphisms on agarose gel. A) MMP-2 (-1306C/T) genotypes. Lane M DNA marker, lane 2 CT genotype, lanes 3, 4, 5 CC genotype. B) MMP-9 (-1562C/T) genotypes. Lane M DNA marker, lanes 1, 3, 4, 5, 7CC genotype, lane 2 TT genotype, lanes 6, 8 CT genotype. C) MMP-2 (-1306C/T) genotypes, lane 1, 2, 3 CC genotype, lane 4 TT genotype

noma. Even if a larger sample size results in significance, it may still not be useful enough for the identification and screening of ESCC.

We would like to thank Dr Nasrin Shojaee for her worthwhile advice.

The authors declare no conflict of interest.

\section{References}

1. Parkin DM, Bray F, Ferlay J, Pisani P. Global cancer statistics, 2002. CA Cancer J Clin 2005; 55: 74-108.

2. Kollarova H, Machova L, Horakova D, Janoutova G, Janout V. Epidemiology of esophageal cancer - an overview article. Biomed Pap Med Fac Univ Palacky Olomouc Czech Repub 2007; 151: 17-28.

3. Jemal A, Bray F, Center MM, Ferlay J,Ward E, Forman D. Global cancer statistics. CA Cancer J Clin 2011; 61: 69-90.

4. Kamangar F, Malekzadeh R, Dawsey SM, Saidi F. Esophageal Cancer in Northeastern Iran: A Review Arch Iran Med 2007; 10: 70-82.

5. Deryugina El, Quigley JP. Matrix metalloproteinases and tumor metastasis. Cancer Metastasis Rev 2006; 25: 9-34.

6. Fanjul-Fernandez M, Folgueras AR, Cabrera S, Lopez-Otin C. Matrix metalloproteinases: evolution, gene regulation and functional analysis in mouse models. BBA 2010; 1803: 3-19.

7. Gialeli C, Theocharis AD, Karamanos NK. Roles of matrix metalloproteinases in cancer progression and theirpharmacological targeting. FEBS J 2010; 278: 16-27.

8. Murphy G, Nagase $\mathrm{H}$. Progress in matrix metalloproteinase research. Mol Aspects Med 2008; 29: 290-308. 
9. Rundhaug. Matrix metalloproteinases, angiogenesis, and cancer. Clin Cancer Res 2003; 9: 551-4.

10. Klein T, Bischoff R. Physiology and pathology of matrix metalloproteases. Amino Acids 2010; 10: 689-726.

11. Amălinei C, Caruntu Id, Giuşcă Se, Anca Bălan R. Matrix metalloproteinases involvement in pathologic conditions. Rom J Morphol Embryol 2010; 51: 215-28.

12. Li Y, Sun D, Duan Y, Zhang X, Wang N. Association of functional polymorphisms in MMPs genes with gastric cardia adenocarcinoma and esophageal squamous cell carcinoma in high incidence region of North China. Mol Biol Rep 2010; 37: 197-205.

13. Miao X, Yu C, Tan W, Xiong P, Liang G, Lu W, Lin D. A Functional Polymorphism in the matrix metalloproteinase-2 gene promoter $(-1306 C / T)$ is associated with risk of development but not metastasis of gastric cardia adenocarcinoma. Cancer Res 2003; 63: 3987-90.

14. Li Y, Ma J, Guo Q, Duan F, Tang F, Zheng P, Zhao Z, Lu G. Overexpression of MMP-2 and MMP-9 in esophageal squamous cell carcinoma. Dis Esophagus 2009; 22: 664-7.

15. Samantaray S, Sharma R, Chattopadhyaya TK, Gupta SD, Ralhan R. Increased expression of MMP-2 and MMP-9 in esophageal squamous cell carcinoma. J Cancer Res Clin Oncol 2004; 130: 37-44.

16. Lane DP, Midgley C, Hupp TR, Lu X, et al. On the regulation of the p53 tumor suppressor, and its role in the cellular response to DNA damage Philos Trans R Soc Lond B Biol Sci 1995; 347: 83-7.

17. Lum A, Le Marchand L. A simple mouthwash method for obtaining genomic DNA in molecular epidemiological studies. Cancer Epidemiol Biomarkers Prev 1998; 7: 719-24.

18. Zhai X, Wang H, Zhu X, Miao H,et al. Gene polymorphisms of ABC transporters are associated with clinical outcomes in children with acute lymphoblastic leukemia. Arch Med Sci 2012; 4: 659-71.

19. Chaudhary AK, Singh M, Bharti AC, Asotra K, Sundaram S, Mehrotra R. Genetic polymorphisms of matrix metalloproteinases and their inhibitors in potentially malignant and malignant lesions of the head and neck. J Biomed Sci 2010; 17: 1-13.

20. Price SJ, Greaves DR,Watkins H. Identification of Novel, Functional Genetic Variants in the Human Matrix Metalloproteinase-2 Gene. J Biol Chem 2001; 276: 7549-58.

21. Yu C, Pan K, Xing D, Liang G, Tan W, Zhang L, Lin D. Correlation between a single nucleotide polymorphism in the matrix metalloproteinase-2 promoter and risk of lung cancer. Cancer Res 2002; 62: 6430-3.

22. Zhou Y, Yu C, Miao X, Tan W, Liang G, Xiong P, Sun T, Lin D. Substantial reduction in risk of breast cancer associated with genetic polymorphisms in the promoters of the matrix metalloproteinase- 2 and tissue inhibitor of metalloproteinase-2 genes. Carcinogenesis 2004; 25: 399-404.

23. Ohtani H MNaMY. Functional polymorphisms in the promoter regions of matrix metalloproteinase-2, -3, -7, -9 and TNF-alpha genes, and the risk of colorectal neoplasm in Japanese. Yonago Acta Medica 2009; 52: 47-56.

24. Ayşegül B, Veysi GH, Muzaffer M, Irfan D, Azra A, Hulyam K. Is a single nucleotide polymorphism a risk factor for lung cancer in the matrix metalloproteinase-2 promoter? Mol Biol Rep 2011; 38: 1469-74.

25. Elander N, Söderkvist P, Fransén K. Matrix metalloproteinase (MMP) -1, -2, -3 and -9 promoter polymorphisms in colorectal cancer. Anticancer Res 2006; 26(1B): 791.

26. Langers AM, Verspaget HW, Hommes DW, Sier CF. Single-nucleotide polymorphisms of matrix metalloproteinases and their inhibitors in gastrointestinal cancre. World J Gastrointest Oncol 2011; 3: 79-98.

27. Peng B, Cao L, Ma X, Wang W, Wang D, Yu L. Meta-analysis of association between matrix metalloproteinases 2, 7 and 9 promoter polymorphisms and cancer risk. Mutagenesis 2010; 25: 371-9.

28. Xu E, Xia X, Lu B, Huang Q. Association of matrix metalloprotein ase-2 and -9 promoter polymorphisms with colorectal cancer in Chinese. Mol Carcinog 2007; 46: 924-9.

29. Nasr HB, MS, Chahed K, Bouaouina N, et al. Matrix metalloproteinase-1 (-1607) $1 \mathrm{G} / 2 \mathrm{G}$ and -9 (-1562) C/T promoter polymorphisms: Susceptibility and prognostic implications in nasopharyngeal carcinomas. Clin Chim Acta 2007; 384: 57-63.
30. Rollin J, Regina S, Vour'h P, lochmann S. Influence of MMP-2 and MMP-9 promoter polymorphisms on gene expression and clinical outcome of non-small cell lung cancer. Lung Can 2006; 56 : 273-80.

31. Jormsjö S, Ye S, Moritz J, et al. Allele-specific regulation of matrix metalloproteinase-12 gene activity is associated with coronary artery luminaldimensions in diabetic patients with manifest coronary artery disease. Circ Res 2000; 86: 998-1003.

32. Kader AK, Shao L, Dinney CP, et al. Matrix metalloproteinase polymorphisms and bladder cancer risk. Cancer Res 2006; 66: 11644-8.

33. Sadjadi A, Marjani H, Semnani S, Nasseri-Moghaddam S. Esophageal cancer in Iran: a review. MEJC 2010; 1: 5-14.

\section{Address for correspondence}

\section{Haniehsadat Eftekhary}

Institute of Biochemistry and Biophysics

University of Tehran

Englab square, Englab Aven

13145-1384 Tehran, Iran

e-mail: h.eftekhari@ibb.ut.ac.ir

Submitted: 2.06 .2013

Accepted: $\quad 16.10 .2013$ 